\title{
Comunicación intercultural en instifuciones públicas de la salud: Validación de la Escala de Conflicto Comunicacional en Organizaciones Interculturales (ECCOI)
}

\author{
Mariana Lazzaro-Salazar y Lucas Pujol-Cols
}

El estudio de los conflictos comunicacionales entre profesionales migrantes y nacionales en contextos laborales contribuye a identificar diferencias en normas y expectativas culturales de la comunicación que pueden contribuir a la generación de conflictos y/o malestar laboral que afecten tanto el quehacer profesional como las relaciones interpersonales entre colegas. Este artículo presenta el estudio de validación de la Escala de Conflicto Comunicacional en Organizaciones Interculturales (ECCOI), diseñada en el contexto del proyecto Fondecyt $N^{\circ} 3160104$ que indaga sobre la comunicación intercultural en instituciones de la salud pública en Chile. Los resultados de los análisis practicados revelaron que la ECCOI exhibe propiedades psicométricas satisfactorias en términos de su validez de contenido, consistencia interna, estructura factorial, validez convergente y validez discriminante, y que, por lo tanto, resulta adecuada para examinar el conflicto comunicacional en contextos organizacionales interculturales.

Palabras claves: comunicación intercultural, conflicto comunicacional, médicos, cultura, migrantes.

Intercultural communication in public bealth institutions: Validation of the Communicational Conflict Scale for Intercultural Organizations (in Sp. ECCOI). The study of communicative conflicts between migrant and national professionals in the workplace helps to identify differences in cultural norms and expectations of communication that can contribute to the generation of conflicts and/or work discomfort that affect both professional performance and interpersonal relationships among colleagues. This article presents the validation study of the Communicational Conflict Scale for Intercultural Organizations 
(in Sp. ECCOI), designed in the context of the Fondecyt project No. 3160104 that investigates intercultural communication in public health institutions in Chile. The results of the analyzes revealed that the ECCOI exhibits satisfactory psychometric properties in terms of its content validity, internal consistency, factor structure, convergent validity and discriminant validity, and that, therefore, it is adequate to examine communicational conflict in intercultural organizations.

Keywords: intercultural communication, communicational conflict, physicians, culture, migrants.

\section{Introducción}

En consideración de los crecientes niveles de interculturalidad que evidencian las organizaciones alrededor del mundo, el presente artículo reporta la validación de una encuesta que se creó con el fin de investigar los conflictos comunicacionales entre médicos extranjeros y nacionales en Chile, abordando este conflicto desde una perspectiva holística al considerar no solo su intensidad y frecuencia (como comúnmente se hace en estudios interculturales, ej. Chan y Goto 2003), sino también investigando las preferencias por estrategias de manejo del conflicto y de uso de lenguaje directo e indirecto.

La diversidad cultural que caracteriza a las organizaciones alrededor del mundo presenta el desafío de explorar una variedad de escenarios comunicacionales con el fin de abordar cuestiones culturalmente sensibles de interacción social en el lugar de trabajo (Schnurr y Zayts 2017; Lazzaro-Salazar 2013). Cada cultura codifica sus conocimientos, creencias, valores e ideas a través de sus sistemas lingüísticos, los cuales son utilizados de diversas formas para expresar e interpretar mensajes (Holland y Quinn 1987; Sharifian 2017). Las formas a través de las cuales se expresan e interpretan los mensajes varían de cultura en cultura y la interacción entre diversos grupos sociales refleja diferencias en las normas y expectativas interaccionales que muy frecuentemente resultan en conflictos comunicacionales (Lazzaro-Salazar y Pujol-Cols 2017). En contextos organizacionales, estos conflictos pueden impedir el desarrollo de relaciones positivas entre los trabajadores, así como también incidir negativamente sobre su rendimiento laboral (2017), por lo que investigar la comunicación intercultural en las organizaciones es de vital relevancia en contextos con crecientes niveles de interculturalidad, como lo es el caso de Chile.

En parte debido a los acelerados procesos de globalización, la movilidad profesional de los trabajadores ha aumentado en los últimos años 
en, por ejemplo, Europa (Horner y Weber 2008), los EE.UU. (Harvey et al. 2004), Costa Rica (Ramos et al. 2015), Brasil (Latinoamericano 2017) y, especialmente, Chile (por ej., Lazzaro-Salazar y Pujol-Cols 2017; Stefoni et al. 2017). Según reportes del Departamento de Extranjería y Migración (EMOL 2018), el promedio de inmigrantes en Chile es de $6.1 \%$ sobre el total de la población, lo que ha significado un aumento de la población inmigrante de aproximadamente $78.5 \%$ desde 2006 (CASEN 2015). En este sentido, el crecimiento económico y la estabilidad de Chile en el contexto latinoamericano han, naturalmente, atraído a extranjeros calificados, principalmente procedentes de la región, en busca de mejores salarios, mejores oportunidades laborales y estabilidad social (ver Urzúa et al. 2015). Chile también ha logrado atraer inmigración de países más lejanos como China, Alemania, EE.UU. y España, quienes se han beneficiado de su apertura a recibir inversiones extranjeras para nuevos negocios. Naturalmente, a medida que Chile continúa creciendo económicamente, continúa desarrollando estrategias que promueven la integración entre países (ver Editorial El Mercurio 2015) y atrayendo a inmigrantes calificados (EFE 2013), la tasa de inmigración también seguirá aumentando y las cuestiones de integración social, tales como la comunicación intercultural, serán cada vez más apremiantes. Con esto en mente, el gobierno chileno ha expresado su voluntad de desarrollar nuevas políticas que reflejen la realidad de la población inmigrante para fomentar la inclusión social y las relaciones positivas entre personas de diferentes culturas (Matus 2014), para lo cual resulta vital investigar la situación social de la inserción laboral de extranjeros en diversas organizaciones del país (Editorial La Tercera 2015).

En este sentido, esta diversidad cultural en las organizaciones presenta a los trabajadores inmigrantes el desafío de adaptarse a las normas sociales del país de acogida y a los trabajadores nacionales el de adoptar nuevas culturas extranjeras. En este contexto, la comunicación intercultural es fundamental ya que los trabajadores deben aprender nuevas formas de comunicarse efectivamente con personas de diversas culturas (Ulrey y Amason 2001). Así, el origen cultural de una persona influye en el comportamiento comunicativo al mismo tiempo que este también está influenciado por las normas y prácticas sociales de una institución laboral (Holmes et al. 2011). Esta visión, comúnmente adoptada en los estudios interculturales actuales (Lazzaro-Salazar 2009; 2013), enfatiza la importancia del lenguaje como una práctica social, como una forma de realizar acción social (Roberts y Sarangi 2005). Como señalan Fairclough y Wodak (1997), el estudio del lenguaje es central para la comprensión de los fenómenos organizacionales, ya que el lenguaje constituye y está constituido por la práctica social. En este sentido, el estudio de la comunicación intercultural permite investigar el uso del lenguaje como parte 
del contexto de interacción definido social y culturalmente (Paltridge 2007), con el objetivo de obtener conocimiento sobre cómo los profesionales extranjeros interpretan y comunican significados al interactuar con profesionales nacionales y con otros extranjeros.

Independientemente de si los interactuantes hablan idiomas diferentes (Lindhout et al. 2012) o el mismo idioma (Holmes y Marra 2002; Lazzaro-Salazar y Pujol-Cols 2017), personas de diferentes orígenes culturales tienen diferentes conceptualizaciones socioculturales de lo que constituye el comportamiento social apropiado con respecto a, por ejemplo, las formas de participación en una conversación y el uso de recursos discursivos (Gunnarsson 2013). Como consecuencia, las expectativas de una persona sobre cómo una reunión, por ejemplo, se debe desarrollar para que observe las necesidades identitarias de sus participantes variará de acuerdo al origen cultural de los interactuantes (Scollon y Scollon 2001). Este enfoque sobre la comunicación intercultural contribuye a la comprensión de esta a un nivel micro social, es decir, qué recursos y estrategias discursivas utilizan los hablantes en la interacción local y cómo, y a un nivel macro social, esos recursos y estrategias discursivas se utilizan para reproducir estructuras sociales y posicionamientos culturalmente definidos. Idealmente, entendimientos, suposiciones e interpretaciones similares de los fenómenos comunicativos contribuyen a mejorar las relaciones positivas en el lugar de trabajo y, a su vez, a un mejor rendimiento laboral (Harvey et al. 2004). Sin embargo, en contextos interculturales, las barreras de comunicación y el conflicto entre las expectativas de comunicación pueden propiciar relaciones insatisfactorias en el lugar de trabajo. Esto, a su vez, puede generar tensiones entre compañeros de trabajo y superiores, y un desempeño laboral deficiente. Comprender entonces cómo interactúan los profesionales de diferentes culturas y cómo se perciben tales interacciones en contextos organizacionales es de vital importancia para la identificación, manejo y prevención de posibles problemas de comunicación que conlleven a conflictos interpersonales.

Este interés por el estudio de la comunicación en organizaciones caracterizadas por altos niveles de interculturalidad entre sus trabajadores motivó el proyecto Fondecyt $\mathrm{N}^{\circ} 3160104$, titulado Comunicación e interculturalidad en instituciones de la salud pública en Chile, que buscó identificar barreras y expectativas de comunicación de los profesionales extranjeros de la salud en tres contextos comunicacionales, a saber, conflictos comunicacionales, conversación de contacto (o small talk) y humor. El presente artículo reporta la validación de la encuesta que se creó en el contexto de este estudio para investigar los conflictos comunicacionales entre médicos extranjeros y nacionales de acuerdo a las percepciones de los primeros. 


\section{Escala de Conflicto Comunicacional en Organizaciones Interculturales (ECCOI)}

La comunicación intercultural es muy frecuentemente estudiada a través de la identificación de aquellos conflictos comunicacionales que impiden la expresión y/o interpretación apropiada de mensajes. Por ejemplo, Clyne (1996) explora el uso 'incorrecto' de varios actos de habla en interacciones interculturales y cómo estos provocan quiebres en la comunicación (también Piller 2017). En este sentido, Brew y Cairns (2004: 332, traducción propia) explican que "el conflicto es una parte natural de las actividades diarias de cualquier lugar de trabajo, pero cuando las personas de diferentes orígenes culturales interactúan, pueden surgir complicaciones más allá de las habituales, debido a una variedad diferente de necesidades y/o diferentes estilos de negociación de conflictos." Así, por ejemplo, la forma en la que se realiza una queja está mediada por las ideas de los interactuantes sobre, por ejemplo, la manera en la que se debe expresar la solidaridad como una forma de enfrentar el conflicto entre compañeros de trabajo y superiores (Euwema y Van Emmerik 2007), mientras que en su estudio Brew y Cairns (2004) también muestran cómo los estilos de comunicación de los interactuantes difieren según sus orígenes culturales, debido a que sus diferentes orientaciones individualistas-colectivistas pueden predecir su preferencia por estrategias de comunicación más directas o indirectas al manejar conflictos laborales. Estos estudios demuestran la importancia de considerar no solo cuales son los aspectos comunicacionales que causan conflicto, sino también la forma en la que estos son manejados, ya que la violación de las normas pragmáticas de comunicación provocan conflictos comunicacionales que a la vez pueden ser responsables de causar desavenencias interpersonales en las organizaciones (Boxer 2002; ver por ejemplo, estrés por aculturación en Ulrey y Amason 2001; y Lazzaro-Salazar y Pujol-Cols 2017).

A la luz de estos aportes científicos, y con el fin de responder los objetivos planteados en el proyecto Fondecyt $\mathrm{N}^{\circ} 3160104$, es decir, investigar a) las estrategias discursivas utilizadas por médicos migrantes para comunicarse con médicos nacionales, b) cuán exitosas perciben que son estas estrategias, y c) las expectativas de comunicación de los médicos migrantes, se diseñó la Escala de Conflicto Comunicacional en Organizaciones Interculturales (ECCOI) con tres dimensiones que miden a) la intensidad $\mathrm{y}$ frecuencia del conflicto comunicacional, b) estrategias de manejo del conflicto comunicacional y c) la preferencia por el lenguaje directo/indirecto. Cabe señalar que, como se ha demostrado, aunque el conflicto comunicacional ha sido abordado con anterioridad en diversos estudios 
interculturales (ej. Chan y Goto 2003), no se ha podido encontrar ninguna escala que mida las tres dimensiones aquí propuestas de conflicto comunicacional en la interacción intercultural.

\subsection{Intensidad y frecuencia del conflicto comunicacional}

Para esta dimensión se adaptaron algunos de los reactivos presentes en la Role Conflict and Ambiguity Scale (Rizzo et al. 1970) y la Cultural Intelligence Scale (Ang et al. 2007), los cuales fueron posteriormente traducidos al castellano por la autora principal, quien es bilingüe en español e inglés.

\subsection{Estilos de manejo del conflicto comunicacional}

Para esta dimensión se adaptaron reactivos del Rabim Organizational Conflict Inventory-II (Rahim 1983; 2001) y el Dutch Test for Conflict Handling (DUTCH) validada en De Dreu et al. (2001), al mismo tiempo que se utilizaron los estilos de manejo de conflicto identificados en estas (es decir, integrativo, complaciente, dominante, evitativo y comprometido; en Landaeta y Grün 2011) en la versión original de la ECCOI (ver también Euwema y Van Emmerik 2007; Ting-Toomey et al. 1991).

\subsection{Preferencia por estilo de lenguaje directo/indirecto}

Como se mencionó anteriormente, la preferencia por el uso de un estilo de comunicación directo o indirecto, es decir formas explícitas o implícitas de comunicación verbal (Shachaf 2008), funciona como indicador de una orientación individualista o colectivista de resolución del conflicto (Brew y Cairns 2004; Hammer 2005). En particular, el uso del lenguaje directo/indirecto ha sido ampliamente estudiado en la comunicación intercultural ya que el uso de uno u otro estilo es interpretado de diferentes formas (por ejemplo, como agresivo o sincero en el caso del lenguaje directo) dependiendo del bagaje cultural de los interactuantes (Shachaf 2008; Fong 1998). Es por esto que esta dimensión adquiere especial relevancia para el estudio y los reactivos que la componen fueron diseñados en base a la amplia literatura existente sobre este tema (ej. Ting-Toomey y Kurogi 1998; BlumKulka 1987).

Por último, aquellos reactivos de las tres dimensiones que componen la ECCOI que fueron diseñados para los propósitos de este estudio se formularon en base a la literatura revisada (ej. Posthuma et al. 2006) y a

Lengua y migración / Language and Migration 12:1 (2020), 123-148

Edición impresa: ISSN 1889-5425. Edición en línea: ISSN 2660-7166. (C) Universidad de Alcalá 
la experiencia previa de los investigadores en el estudio del conflicto comunicacional (ej. Lazzaro-Salazar et al. 2015; Holmes et al. 2017) y de comunicación intercultural en ámbitos laborales (ej. Lazzaro-Salazar 2009; 2013; 2016; 2017a, b).

\section{Contexto del estudio}

Se decidió realizar el estudio en instituciones públicas de la salud de Chile debido a que las olas de inmigración que afectan al país son particularmente evidentes en la composición sociodemográfica de sus médicos, situando las consideraciones sobre el impacto de los trabajadores sanitarios migrantes en la vida organizacional y la efectividad de la práctica médica al seno de los esfuerzos de investigación. Los médicos migrantes en Chile constituyen el $17.9 \%$ de la fuerza laboral médica total del país y el $32 \%$ del personal médico que trabaja en instituciones de salud pública (CASEN 2015; La Tercera octubre de 2015), lo que coloca a Chile en el quinto lugar entre los países de la Organización para la Cooperación y el Desarrollo Económicos (en adelante, OCDE; Estadísticas OCDE 2017) con mayor porcentaje de médicos extranjeros (en comparación con Israel con $57,7 \%$ e Italia con $0,83 \%$ ). Estos médicos provienen predominantemente de Venezuela, Colombia y Cuba, y se han trasladado a Chile por razones de seguridad personal, por avance económico y por inestabilidad política en sus países de origen (Lazzaro-Salazar y Pujol-Cols 2017; Zayts y Lazzaro-Salazar 2017a).

Hasta hace poco, el impacto de esta configuración intercultural de las instituciones de la salud en Chile ha motivado principalmente la investigación desde los campos de las políticas públicas y de la salud mental al, por ejemplo, evaluar la implementación de programas socioculturales que apuntan a identificar y abordar las diferencias culturales para la inclusión de las comunidades indígenas en el sistema público de salud de Chile (ej. Pérez et al. 2016), e investigar los mecanismos de afrontamiento en los procesos de aculturación experimentados por pacientes migrantes en Chile (ej. Urzúa et al. 2016). Sin embargo, no se han podido encontrar estudios que exploren la comunicación intercultural y las relaciones profesionales entre médicos migrantes y nacionales en instituciones públicas de la salud en Chile desde una perspectiva sociolingüística, por lo que el presente estudio es el primero en abordar este tema desde el contexto de los conflictos comunicacionales (ej. Lazzaro-Salazar y Pujol-Cols 2017; Zayts y Lazzaro-Salazar 2017a; 2017b) a través de la ECCOI sobre la cual se presentan los resultados de su validación a continuación. 


\section{Método}

\subsection{Diseño}

Se utilizó un diseño no experimental (es decir, no existe una manipulación deliberada de las variables sometidas a medición), correlacional (es decir, se describe el comportamiento de las variables incluidas en la investigación, así como las relaciones entre ellas) y de corte transversal (es decir, las variables son medidas en un único momento temporal), con el propósito de examinar las propiedades psicométricas de la Escala de Conflicto Comunicacional en Organizaciones Interculturales (ECCOI) en términos de su validez de contenido, confiabilidad, estructura factorial, validez convergente y validez discriminante (ver punto 5 ). Es necesario destacar que esta escala forma parte de un proyecto más amplio sobre la comunicación intercultural en instituciones públicas de la salud en Chile, el cual fue aprobado por el Comité de Ética de la Universidad Católica del Maule (Acta \#28/2015; Acta de seguimiento \#57/2017; Acta de Finalización \#150/2018).

\subsection{Participantes}

Se recurrió a una muestra no probabilística compuesta por ochenta médicos migrantes que trabajan en instituciones públicas de la salud de las regiones de Antofagasta (en el norte), El Maule (en el centro) y Magallanes (en el sur) de Chile. El 53,75\% de los participantes fueron mujeres y el $46,25 \%$ hombres. El 8,75\% tenía 30 años o menos, el $25,00 \%$ entre 31 y 35 años, el $40,00 \%$ entre 36 y 40 años, el $15,00 \%$ entre 41 y 45 años y el $11,25 \%$ restante entre 46 y 50 años. Con respecto a la especialidad médica, el $16,25 \%$ de los médicos participantes eran pediatras, el 7,50\% cirujanos, el 15,00\% anestesiólogos y el $20,00 \%$ médicos generales. El restante $41,25 \%$ de la muestra se conformó por ginecólogos, cardiólogos, hematólogos, intensivistas, ortopedistas, radiólogos e internistas.

\subsection{Instrumento}

La escala ECCOI está compuesta por tres secciones. La primera tiene por propósito medir el grado de intensidad y frecuencia con la que los participantes perciben la existencia de conflictos comunicacionales en su lugar de trabajo (ej. "Me siento desmotivado/a como resultado de conflictos de comunicación”). La segunda se focaliza en los estilos 
empleados por los participantes para hacer frente a los conflictos comunicacionales percibidos (ej. "Debo adaptar mi forma de comunicarme con los colegas chilenos"). La tercera se refiere al grado de preferencia que los participantes tienen por el uso de un estilo comunicacional directo o indirecto (ej. "Me incomoda el uso de lenguaje indirecto"). La versión original de la encuesta se compuso por 70 reactivos y dos escalas de Likert de cinco niveles para medir grado de acuerdo y frecuencia de las situaciones mencionadas en la escala.

\subsection{Procedimiento}

Puesto que los médicos migrantes constituyen una población de difícil acceso (ver el concepto de población oculta en Penrod et al. 2003), al estar compuesta por un número reducido de individuos y, al mismo tiempo, por constituir un grupo social vulnerable, se utilizó una técnica de muestreo de bola de nieve para identificar a los potenciales participantes (Goodman 1961). De este modo, el primer autor de este artículo se comunicó primeramente con las máximas autoridades de las instituciones de salud y les solicitó que proporcionaran los datos de contacto de su planta de médicos migrantes, quienes, una vez contactados, sirvieron de nexo para identificar otros potenciales participantes. Esta metodología de muestreo no solo suele resultar útil para ganar acceso a los participantes cuando estos provienen de una población oculta, sino también para estimular su involucramiento en la investigación. Los potenciales participantes fueron contactados por correo electrónico y/o por mensaje de texto (de acuerdo a sus preferencias) y se los invitó a llenar la encuesta en línea. La misma se compuso por una descripción del estudio y un formulario de consentimiento informado, otorgándose acceso a la encuesta solo cuando este último fuera aceptado. Las respuestas a la encuesta fueron anónimas y cualquier información personal que permita identificar a los participantes y las instituciones donde trabajan es estrictamente confidencial. Los datos reportados en este artículo fueron recogidos entre septiembre de 2016 y septiembre de 2017.

\section{Análisis}

\subsection{Validez de contenido}

La validez de contenido, entendida como el grado en que el conjunto de ítems que integran el cuestionario constituyen una muestra representativa del dominio de contenido que se pretende medir, fue examinada a través del juicio de expertos (Lawshe 1975; Tristán-López 2008). Esta 
evaluación fue realizada por cuatro jueces expertos chilenos e internacionales (una doctora en lingüística, dos doctores en psicología y un médico) con amplia experiencia en diseño y validación de encuestas y en investigaciones de temas relacionados con los de esta escala. Siguiendo las recomendaciones de Escobar-Pérez y Cuervo-Martínez (2008), los jueces completaron una planilla que contenía una descripción breve del proyecto, sus objetivos de estudio, una definición de conflictos comunicacionales (donde se los identifica como 'aquellos comportamientos verbales o no verbales que dificultan o impiden la comunicación fluida entre colegas, sean estas diferencias en el uso de vocabulario, pronunciación, formas de decir y/o entender las cosas, etc.'), descripción detallada de la encuesta, sus dimensiones y lo que se esperaba obtener como resultado de su aplicación, y una grilla donde los jueces debían evaluar la claridad, coherencia y relevancia de cada uno de los ítems de la escala según su grado de acuerdo (desde $1=$ no cumple con el criterio al $4=$ alto nivel). Si bien en términos generales la escala fue valorada de forma positiva, como resultado de esta etapa del estudio se eliminaron 12 ítems los cuales fueron evaluados de forma negativa por todos los jueces expertos. Por otra parte, las observaciones y comentarios realizados por los jueces sobre los ítems se vincularon con aspectos léxicos de éstos. De acuerdo a esto, palabras como 'pares' fueron cambiadas por 'colegas' y se agregó 'en Chile' y 'chilenos' en muchos de los ítems para evitar confusiones con otros contextos laborales donde se hayan desempeñado los médicos participantes.

\subsection{Estudio piloto y adaptación semántica}

Se administró una versión preliminar del instrumento a una muestra no probabilística compuesta por 34 médicos migrantes que trabajan en instituciones públicas de la salud en la Región de El Maule, en el centro de Chile. Este estudio piloto no solo permitió evaluar el grado en que los participantes comprendían adecuadamente los reactivos del cuestionario (es decir, su validación semántica) sino también observar, aunque de modo preliminar, el comportamiento de sus medias, desviaciones estándar y correlaciones, así como la sensibilidad del coeficiente alfa de Cronbach ante modificaciones en los mismos. Como resultado de los análisis practicados, se eliminaron 17 ítems (ver las tablas A1, A2 y A3 del anexo).

\subsection{Confiabilidad}

La confiabilidad de las tres sub-escalas que componen el instrumento fue analizada en términos de su consistencia interna, para lo que se cal-

Lengua y migración / Language and Migration 12:1 (2020), 123-148

Edición impresa: ISSN 1889-5425. Edición en línea: ISSN 2660-7166. (C) Universidad de Alcalá 
culó el coeficiente alfa de Cronbach. Valores superiores a 0,70 indican una consistencia interna satisfactoria (Nunnally y Bernstein 1994), si bien existen algunos autores (ej. Loewenthal 2001) que proponen que coeficientes superiores a 0,60 también resultan aceptables en estudios de validación. La escala de 41 reactivos que resultó de la combinación de las etapas anteriores (ver Anexo, secciones 1 a 3 ) fue sometida a un análisis de sensibilidad del coeficiente alfa. Con sustento en aquel, un total de 14 ítems fueron eliminados puesto que reducían el valor del coeficiente alfa de Cronbach, quedando la versión final de la escala conformada por 27 ítems. Esta última versión es la que fue empleada para realizar el resto de las pruebas psicométricas, cuyos resultados son presentados a continuación.

\subsection{Estructura factorial}

La estructura factorial de las tres sub-escalas que componen el instrumento fue examinada mediante un análisis factorial de componentes principales, con una solución final basada en una rotación varimax. La rotación de factores es un procedimiento que busca, a partir de la solución inicial, lograr una matriz de cargas factoriales que facilite la interpretación, dando así cumplimiento al denominado principio de estructura simple (Thurstone 1935). Este último señala que la matriz de cargas factoriales debe reunir las siguientes características: (a) cada factor debe observar solo algunas cargas factoriales elevadas y las restantes próximas a cero; (b) cada variable no debe estar saturada en más de un factor; (c) no deben existir factores con la misma distribución en sus cargas factoriales. Bajo estos principios, cada factor observará una correlación alta con un grupo de variables y baja con las restantes. El método varimax, en particular, propone que, si se logra aumentar la varianza de las cargas factoriales al cuadrado de cada factor (consiguiendo de este modo que algunas de sus cargas factoriales tiendan a acercarse a 1 mientras que otras se acercan a 0 ) es posible obtener una pertenencia más clara e inteligible de cada variable a ese factor. Siguiendo las recomendaciones de Thompson (2004), solo se consideraron en la interpretación de contenidos las saturaciones superiores a 0,30 y fueron excluidos los factores que no dieran cumplimiento al criterio de la raíz latente. Previo al análisis factorial de componentes principales, se verificó que la matriz de correlaciones inter-elementos resultara adecuada para la aplicación de este modelo, por medio del cálculo de la medida de adecuación muestral de Kaiser-Meyer-Olkin y de la prueba de la esfericidad de Bartlett (Hair et al. 1995). 


\subsection{Validez convergente}

La validez convergente se refiere al grado en que las variables observadas correspondientes a un constructo (en este caso, los reactivos del cuestionario) observan correlaciones elevadas entre sí. Siguiendo el procedimiento recomendado por Fornell y Larcker (1981), se procedió a estimar las cargas factoriales estandarizadas para cada reactivo y, luego, la varianza media extraída (VME) para cada factor latente. Niveles de VME superiores a 0,40 fueron considerados indicadores de una adecuada validez convergente, al tratarse este estudio del primer antecedente de validación del instrumento (Fornell y Larcker 1981; véase también Huang et al. 2013).

\subsection{Validez discriminante}

La validez discriminante es entendida por Fornell y Larcker (1981) como el grado en que dos factores latentes no comparten una varianza sustancial entre sí. En este sentido, existe validez discriminante entre dos variables latentes si la varianza que comparten resulta menor que su VME. Lógicamente, esta manifestación de validez fue examinada únicamente en aquellas sub-escalas que presentaron una estructura multidimensional (es decir, poseen más de un factor latente).

\section{Resultados}

Para cada una de las tres sub-escalas que componen el instrumento se realizó un análisis factorial de componentes principales, con una solución final basada en una rotación ortogonal varimax. De manera previa, se verificó la aplicabilidad del modelo factorial mediante el cálculo de la medida KMO y de la prueba de la esfericidad de Bartlett (Hair et al. 1995). La obtención de estadísticos KMO cercanos y/o superiores al nivel crítico de 0,70 y de diferencias estadísticamente significativas en la prueba de la esfericidad de Bartlett sugirieron condiciones apropiadas para el empleo de la técnica de análisis factorial en las tres sub-escalas (Cureton y D’Agostino 2013).

Como puede observarse en la tabla 1, los resultados del análisis factorial revelaron que los 10 reactivos que refieren al Nivel Percibido de Conflicto Comunicacional saturan claramente en dos factores. El primero de ellos, denominado intensidad del conflicto comunicacional, agrupa los primeros cinco ítems de la encuesta y explica un 16,67\% de la varianza. Los niveles de confiabilidad para este factor resultan satisfactorios $(\alpha=0,81)$, al superar el nivel crítico de 0,70 sugerido por 
Nunnally y Bernstein (1994), pudiendo incluso incrementarse en caso de eliminar el ítem \#5 $(\alpha=0,86)$. El segundo factor es rotulado frecuencia del conflicto comunicacional, el cual incluye los últimos cinco ítems de la encuesta y explica un $43,94 \%$ de la varianza. Nuevamente, se observó que los niveles de confiabilidad para este factor resultan satisfactorios $(\alpha=0,82)$, pudiendo incluso acrecentarse en caso de eliminar el ítem \#5 $(\alpha=0,85)$. Los resultados reportados en la tabla 1 resultan consistentes con lo observado en su correspondiente gráfico de sedimentación (ver figura 1), en el que se aprecia que son dos los factores que logran superar el criterio de la raíz latente. Por otro lado, ambos factores observaron niveles satisfactorios de validez convergente (véase tabla 2), habiendo resultado su VME superior al estándar de 0.40 sugerido por Fornell y Larcker (1981). En cuanto a la validez discriminante, la misma también fue adecuada, habiendo reportado ambos factores una varianza compartida $(0,21)$ inferior a la $\operatorname{VME}(0,52)$.

\begin{tabular}{|c|c|c|c|}
\hline \multirow{2}{*}{ Nivel percibido de conflicto comunicacional } & \multicolumn{2}{|c|}{ Factor } & \multirow{2}{*}{$\begin{array}{l}\text { Alfa si se } \\
\text { elimina el ítem }\end{array}$} \\
\hline & 1 & 2 & \\
\hline \multicolumn{4}{|l|}{ Intensidad del conflicto comunicacional } \\
\hline $\begin{array}{l}\text { Los problemas de comunicación a los que me enfrento en mi } \\
\text { trabajo frecuentemente impiden que realice mis labores } \\
\text { satisfactoriamente. }\end{array}$ & 0,705 & & 0,78 \\
\hline $\begin{array}{l}\text { Los problemas de comunicación a los que me enfrento en mi } \\
\text { trabajo a menudo me impiden desarrollar relaciones positivas } \\
\text { con mis colegas. }\end{array}$ & 0,833 & & 0,76 \\
\hline $\begin{array}{l}\text { Me siento desmotivado/a como resultado de conflictos de } \\
\text { comunicación. }\end{array}$ & 0,808 & 0,314 & 0,74 \\
\hline Experimento ansiedad a causa de conflictos de comunicación. & 0,845 & & 0,72 \\
\hline $\begin{array}{l}\text { Muy frecuentemente los conflictos comunicacionales a los que } \\
\text { me enfrento en mi trabajo terminan en confrontaciones que no } \\
\text { conducen a nada. }\end{array}$ & 0,479 & & 0,86 \\
\hline \multicolumn{4}{|l|}{ Frecuencia del conflicto comunicacional } \\
\hline $\begin{array}{l}\text { Mi forma de comunicación me ha impedido hacer mi trabajo } \\
\text { apropiadamente. }\end{array}$ & & 0,790 & 0,79 \\
\hline $\begin{array}{l}\text { La forma en la que se comunican mis colegas chilenos me ha } \\
\text { impedido hacer mi trabajo adecuadamente. }\end{array}$ & & 0,885 & 0,75 \\
\hline $\begin{array}{l}\text { En mi lugar de trabajo me enfrento a conflictos de comunicación } \\
\text { con mis colegas chilenos. }\end{array}$ & & 0,815 & 0,75 \\
\hline Tengo problemas de comunicación con mis colegas chilenos. & & 0,748 & 0,78 \\
\hline Se burlan de mi forma de hablar. & 0,315 & 0,439 & 0,85 \\
\hline Consistencia interna (Alfa de Cronbach) & 0,81 & 0,82 & \\
\hline Varianza explicada & $16,67 \%$ & $43,94 \%$ & \\
\hline
\end{tabular}

$\mathrm{KMO}=0,79$. Por razones de simplicidad solo se reportan las saturaciones superiores a 0,30.

Tabla 1. Nivel percibido de conflicto comunicacional 


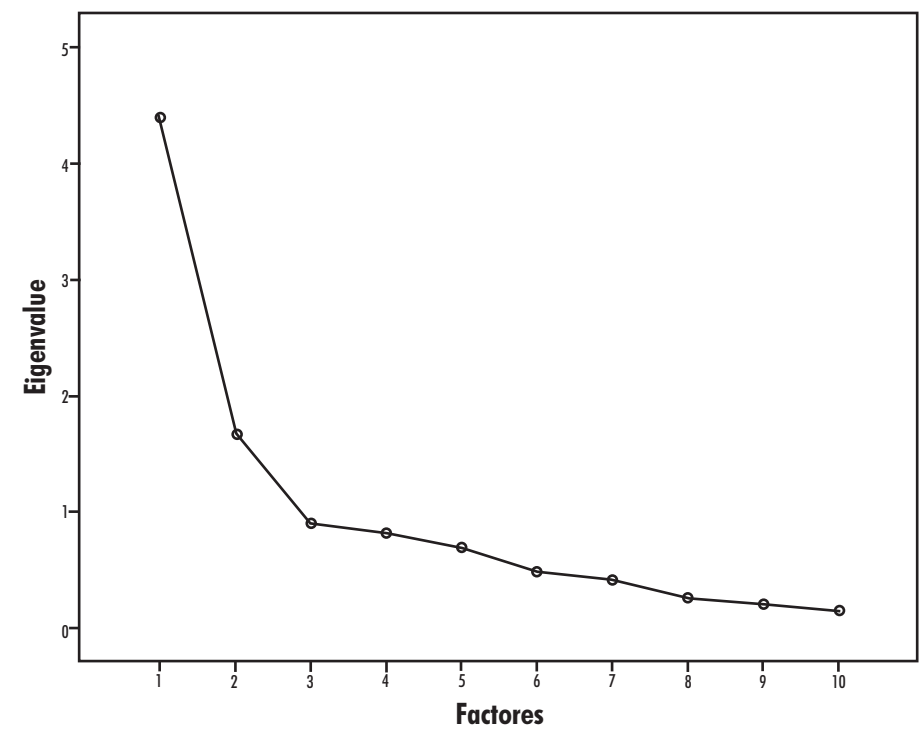

Figura 1. Gráfico de sedimentación para el Nivel Percibido de Conflicto Comunicacional

\begin{tabular}{|l|c|c|c|c|}
\hline \multirow{2}{*}{ Ítem } & \multicolumn{2}{|c|}{ Intensidad del conflicto } & \multicolumn{2}{l|}{ Frecuencia del conflicto } \\
\cline { 2 - 6 } & CFE & CFE $^{2}$ & CFE & CFE $^{2}$ \\
\hline $\begin{array}{l}\text { Los problemas de comunicación a los que me enfrento en } \\
\text { mi trabajo frecuentemente impiden que realice mis labores } \\
\text { satisfactoriamente. }\end{array}$ & 0,63 & 0,40 & & \\
\hline $\begin{array}{l}\text { Los problemas de comunicación a los que me enfrento en } \\
\text { mi trabajo a menudo me impiden desarrollar relaciones } \\
\text { positivas con mis colegas. }\end{array}$ & 0,70 & 0,49 & & \\
\hline $\begin{array}{l}\text { Me siento desmotivado/a como resultado de conflictos de } \\
\text { comunicación. }\end{array}$ & 0,89 & 0,79 & & \\
\hline $\begin{array}{l}\text { Experimento ansiedad a causa de conflictos de } \\
\text { comunicación. }\end{array}$ & 0,90 & 0,81 & & \\
\hline $\begin{array}{l}\text { Muy frecuentemente los conflictos comunicacionales a los } \\
\text { que me enfrento en mi trabajo terminan en } \\
\text { confrontaciones que no conducen a nada. }\end{array}$ & 0,33 & 0,11 & & \\
\hline $\begin{array}{l}\text { Mi forma de comunicación me ha impedido hacer mi } \\
\text { trabajo apropiadamente. }\end{array}$ & & & 0,69 & 0,48 \\
\hline $\begin{array}{l}\text { La forma en la que se comunican mis colegas chilenos me } \\
\text { ha impedido hacer mi trabajo adecuadamente. }\end{array}$ & & & 0,86 & 0,74 \\
\hline $\begin{array}{l}\text { En mi lugar de trabajo me enfrento a conflictos de } \\
\text { comunicación con mis colegas chilenos. }\end{array}$ & & & 0,81 & 0,66 \\
\hline $\begin{array}{l}\text { Tengo problemas de comunicación con mis colegas } \\
\text { chilenos. }\end{array}$ & & & 0,72 & 0,52 \\
\hline Se burlan de mi forma de hablar. & & & 0,43 & 0,18 \\
\hline VME & & & & \\
\hline
\end{tabular}

Notas. CFE = carga factorial estandarizada, $\mathrm{CFE}^{2}=$ carga factorial estandarizada elevada al cuadrado, $\mathrm{VME}=$ varianza media extraída.

Tabla 2. Varianza media extraída para la sub-escala de Nivel Percibido de Conflicto Comunicacional

Lengua y migración / Language and Migration 12:1 (2020), 123-148

Edición impresa: ISSN 1889-5425. Edición en línea: ISSN 2660-7166. (C) Universidad de Alcalá 


\begin{tabular}{|c|c|c|c|c|}
\hline \multirow{2}{*}{ Estilos de manejo del conflicto comunicacional } & \multicolumn{3}{|c|}{ Factor } & \multirow{2}{*}{$\begin{array}{c}\text { Alfa si se } \\
\text { elimina el } \\
\text { ítem }\end{array}$} \\
\hline & 1 & 2 & 3 & \\
\hline \multicolumn{5}{|l|}{ Adaptable } \\
\hline $\begin{array}{l}\text { Debo adaptar mi forma de comunicarme con los } \\
\text { colegas chilenos. }\end{array}$ & & 0,635 & & 0,69 \\
\hline $\begin{array}{l}\text { Tuve que adaptar la forma de comunicarme cuando } \\
\text { comencé a trabajar en Chile. }\end{array}$ & & 0,573 & & 0,72 \\
\hline $\begin{array}{l}\text { Debería mejorar la forma de comunicarme con mis } \\
\text { colegas chilenos. }\end{array}$ & & 0,810 & & 0,65 \\
\hline $\begin{array}{l}\text { Debería cambiar la forma de comunicarme con mis } \\
\text { colegas chilenos. }\end{array}$ & & 0,716 & $-0,310$ & 0,70 \\
\hline $\begin{array}{l}\text { Prefiero adecuarme a la forma de comunicarse de la } \\
\text { otra persona. }\end{array}$ & & 0,686 & 0,335 & 0,71 \\
\hline \multicolumn{5}{|l|}{ Dominante } \\
\hline $\begin{array}{l}\text { Mis habilidades de comunicación son las más } \\
\text { efectivas. }\end{array}$ & & & 0,790 & 0,65 \\
\hline $\begin{array}{l}\text { Mi forma de comunicación ha sido una ventaja } \\
\text { cuando se trata de situaciones conflictivas. }\end{array}$ & & & 0,714 & 0,69 \\
\hline $\begin{array}{l}\text { Sé exactamente lo que se espera de mí en lo que } \\
\text { respecta a la forma de comunicación. }\end{array}$ & & & 0,608 & 0,72 \\
\hline Siento que mi forma de comunicación me beneficia. & & & 0,803 & 0,62 \\
\hline \multicolumn{5}{|l|}{ Evasivo } \\
\hline Prefiero no expresar estar en desacuerdo con alguien. & 0,791 & & & 0,73 \\
\hline Intento no hablar en reuniones de equipo. & 0,845 & & & 0,71 \\
\hline $\begin{array}{l}\text { Prefiero encontrar otro momento para aclarar } \\
\text { malentendidos comunicacionales. }\end{array}$ & 0,694 & & & 0,77 \\
\hline Prefiero dejar pasar los conflictos de comunicación. & 0,618 & 0,376 & & 0,76 \\
\hline $\begin{array}{l}\text { Prefiero no expresar mis opiniones de manera } \\
\text { abierta. }\end{array}$ & 0,664 & & & 0,77 \\
\hline Consistencia interna (Alfa de Cronbach) & 0,79 & 0,74 & 0,73 & \\
\hline Varianza explicada & $26,06 \%$ & $17,92 \%$ & $13,23 \%$ & \\
\hline
\end{tabular}

$\mathrm{KMO}=0,70$. Por razones de simplicidad solo se reportan las saturaciones superiores a 0,30.

Tabla 3. Estilos de manejo del conflicto comunicacional

Con respecto a la sub-escala de Estilos de Manejo del Conflicto Comunicacional, los resultados del análisis factorial de componentes principales revelaron que sus reactivos tienden a saturar claramente en tres factores (ver tabla 2). El primero de ellos, llamado estilo comunicacional evasivo, reúne cinco reactivos y se refiere a la preferencia del interactuante por evitar involucrarse en situaciones potencialmente conflictivas (Landaeta y Grün 2011). Este factor observa una confiabilidad satisfactoria $(\alpha=0,79)$ y explica un $26,06 \%$ de la varianza. El segundo factor, denominado estilo comunicacional adaptable, también reúne cinco reactivos y se refiere a cuando los interactuantes modifi- 
can su comportamiento comunicacional para adaptarse a las normas y los modelos culturales de la comunidad de acogida (ver estilo comprometido en Ting-Toomey et al. 1991). El mismo observa una confiabilidad aceptable $(\alpha=0,74)$ y explica un $17,92 \%$ de la varianza. Finalmente, el tercero de los factores corresponde al estilo comunicacional dominante, conformado por cuatro reactivos, está asociado a "forzar comportamiento para ganar posición" (Landaeta y Grün 2011: 67), a imponer sus propias normas sociales y de comunicación. El estilo dominante también reportó niveles satisfactorios de consistencia interna $(\alpha=0,73)$, explicando un $13,23 \%$ de la varianza. Los resultados presentados en la tabla 3 son consistentes con los diagramados en su correspondiente gráfico de sedimentación (ver figura 2). En cuanto a la validez convergente, los resultados de los análisis practicados revelaron que esta es satisfactoria en las tres dimensiones (ver tabla 4). Lo mismo ocurrió con la validez discriminante, habiéndose obtenido una varianza compartida (estilo adaptable-estilo evasivo $=0,11$; estilo adaptable-estilo dominante $=0,01$; estilo dominante-estilo evasivo $=$ $0,01)$ muy inferior a la VME.

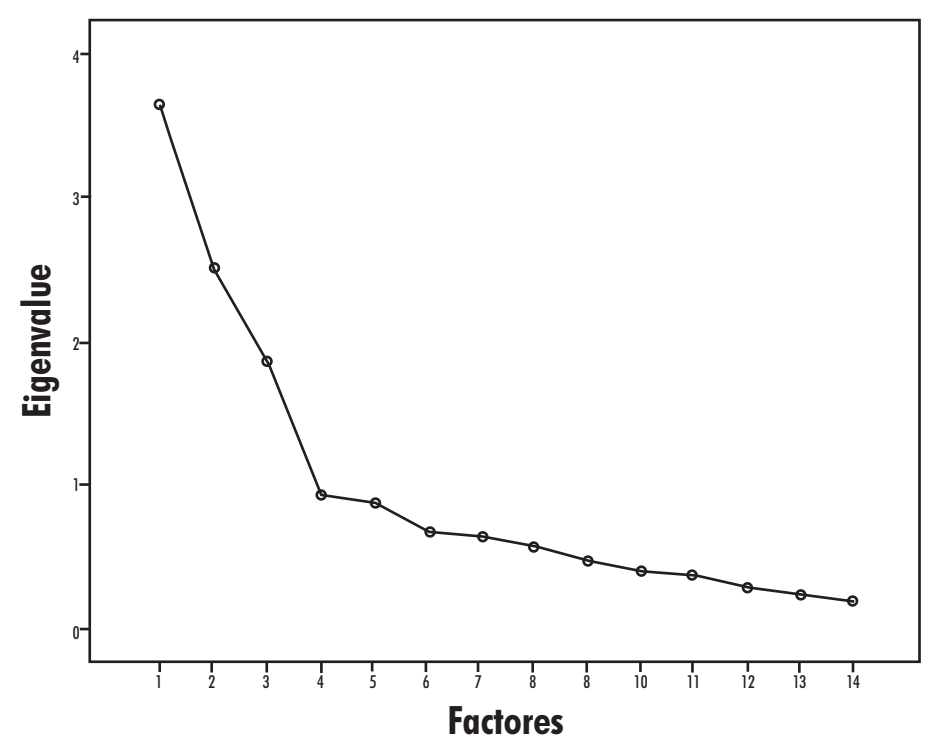

Figura 2. Gráfico de sedimentación para Estilos de Manejo de Conflicto Comunicacional 


\begin{tabular}{|l|c|c|c|c|c|c|}
\hline \multicolumn{1}{|c|}{} & \multicolumn{2}{|c|}{ Adaptable } & \multicolumn{2}{c|}{ Dominante } & \multicolumn{2}{c|}{ Evasivo } \\
\hline & CFE & \multicolumn{1}{c|}{ CFE } & CFE & CFE & CFE & CFE $^{2}$ \\
\hline $\begin{array}{l}\text { Debo adaptar mi forma de comunicarme con los colegas } \\
\text { chilenos. }\end{array}$ & 0,54 & 0,29 & & & & \\
\hline $\begin{array}{l}\text { Tuve que adaptar la forma de comunicarme cuando } \\
\text { comencé a trabajar en Chile. }\end{array}$ & 0,52 & 0,27 & & & & \\
\hline $\begin{array}{l}\text { Debería mejorar la forma de comunicarme con mis } \\
\text { colegas chilenos. }\end{array}$ & 0,79 & 0,62 & & & & \\
\hline $\begin{array}{l}\text { Debería cambiar la forma de comunicarme con mis } \\
\text { colegas chilenos. }\end{array}$ & 0,53 & 0,28 & & & & \\
\hline $\begin{array}{l}\text { Prefiero adecuarme a la forma de comunicarse de la otra } \\
\text { persona. }\end{array}$ & 0,73 & 0,53 & & & & \\
\hline Mis habilidades de comunicación son las más efectivas. & & & 0,70 & 0,49 & & \\
\hline $\begin{array}{l}\text { Mi forma de comunicación ha sido una ventaja cuando se } \\
\text { trata de situaciones conflictivas. }\end{array}$ & & & 0,54 & 0,29 & & \\
\hline $\begin{array}{l}\text { Sé exactamente lo que se espera de mí en lo que respecta } \\
\text { a la forma de comunicación. }\end{array}$ & & & 0,49 & 0,24 & & \\
\hline Siento que mi forma de comunicación me beneficia. & & & 0,81 & 0,66 & & \\
\hline Prefiero no expresar estar en desacuerdo con alguien. & & & & & 0,73 & 0,53 \\
\hline Intento no hablar en reuniones de equipo. & & & & & 0,83 & 0,69 \\
\hline $\begin{array}{l}\text { Prefiero encontrar otro momento para aclarar } \\
\text { malentendidos comunicacionales. }\end{array}$ & & & & & 0,58 & 0,34 \\
\hline Prefiero dejar pasar los conflictos de comunicación. & & & & & 0,64 & 0,41 \\
\hline Prefiero no expresar mis opiniones de manera abierta. & & & & & 0,58 & 0,34 \\
\hline VME & & $0,40,42$ & & 0,46 \\
\hline
\end{tabular}

Notas. CFE = carga factorial estandarizada, $\mathrm{CFE}^{2}=$ carga factorial estandarizada elevada al cuadrado, VME = varianza media extraída.

Tabla 4. Varianza media extraída para la sub-escala de Estilos de Manejo del Conflicto

Finalmente, con respecto a la sub-escala Preferencia por Estilo de Comunicación Directo/Indirecto, los resultados revelaron que la misma refleja una estructura unidimensional, al saturar sus tres reactivos en un único factor latente. Como puede observarse en la tabla 5 , este factor verificó una consistencia interna satisfactoria $(\alpha=0,68)$ y explicó el 59,79\% de la varianza. Estos hallazgos son representados en su correspondiente gráfico de sedimentación (ver figura 3). Asimismo, tal y como puede observarse en la tabla 6, esta sub-escala reportó una validez convergente satisfactoria, reflejada en una VME igual a 0,41 . 


\begin{tabular}{|l|c|c|}
\hline Preferencia de Estilo de Comunicación Directo/Indirecto & Factor & $\begin{array}{c}\text { Alfa si se } \\
\text { elimina el } \\
\text { ítem }\end{array}$ \\
\cline { 2 - 3 } Me siento más cómodo/a comunicando mis opiniones de manera directa. & 0,704 & 0,66 \\
\hline Me incomoda el uso de lenguaje indirecto. & 0,815 & 0,49 \\
\hline Me resulta difícil comprender el lenguaje indirecto. & 0,796 & 0,66 \\
\hline Consistencia interna (Alfa de Cronbach) & 0,68 & \\
\hline Varianza explicada & $59,79 \%$ & \\
\hline
\end{tabular}

$\mathrm{KMO}=0,64$. Por razones de simplicidad solo se reportan las saturaciones superiores a 0,30.

Tabla 5. Preferencia de Estilo de Comunicación Directo/Indirecto

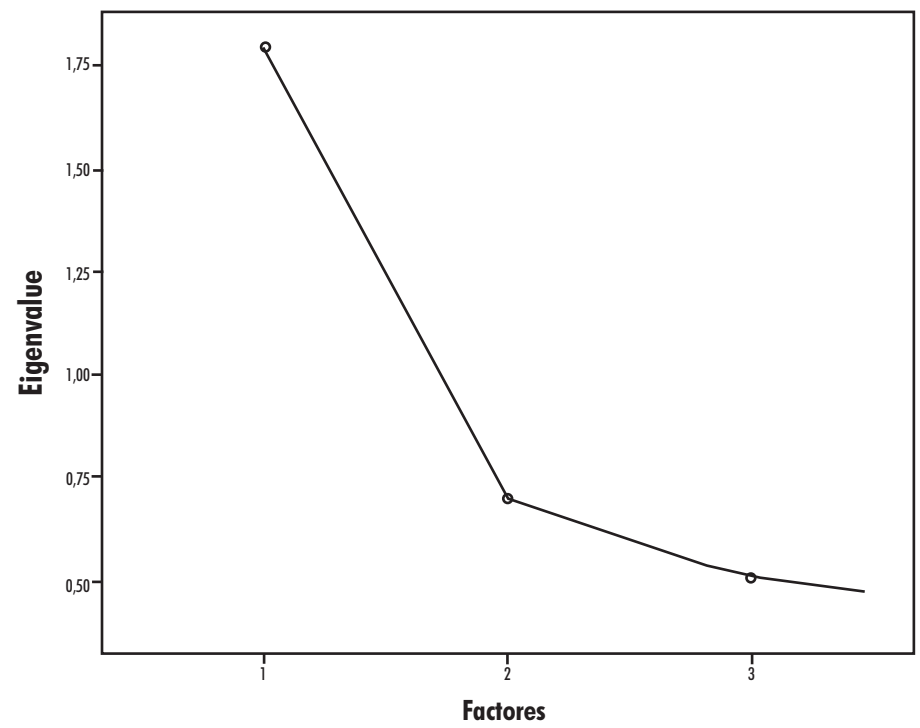

Figura 3. Gráfico de sedimentación para la Preferencia de Estilo de Comunicación Directo/Indirecto

\begin{tabular}{|l|c|c|}
\hline \multirow{2}{*}{\multicolumn{1}{|c|}{ Ítems }} & \multicolumn{2}{c|}{ Adaptable } \\
\cline { 2 - 3 } & CFE & CFE $^{2}$ \\
\hline Me siento más cómodo/a comunicando mis opiniones de manera directa. & 0,49 & 0,24 \\
\hline Me incomoda el uso de lenguaje indirecto. & 0,74 & 0,55 \\
\hline Me resulta difííl comprender el lenguaje indirecto. & 0,67 & 0,45 \\
\hline VME & \multicolumn{2}{|c|}{0,41} \\
\hline
\end{tabular}

Notas. CFE = carga factorial estandarizada, $\mathrm{CFE}^{2}=$ carga factorial estandarizada elevada al cuadrado, VME = varianza media extraída.

Tabla 6. Varianza media extraída para la sub-escala de Preferencia de Estilo de Comunicación Directo/Indirecto

Lengua y migración / Language and Migration 12:1 (2020), 123-148

Edición impresa: ISSN 1889-5425. Edición en línea: ISSN 2660-7166. (C) Universidad de Alcalá 
Habiéndose realizado un examen minucioso de las propiedades psicométricas de la ECCOI, en la tabla 7 se presentan las medias, desviaciones estándar, correlaciones y niveles de confiabilidad para cada una de las dimensiones que integran sus tres sub-escalas centrales. Como puede observarse, si bien la mayoría de ellas exhiben correlaciones estadísticamente significativas entre sí, las mismas resultan moderadas, lo que no pone en riesgo su validez discriminante.

\begin{tabular}{|l|c|c|c|c|c|c|c|c|}
\hline Variable & $\mathrm{M}$ & $\mathrm{DE}$ & 1 & 2 & 3 & 4 & 5 & 6 \\
\hline 1. Intensidad del conflicto & 2,19 & 0,91 & 0,81 & & & & & \\
\hline 2. Frecuencia del conflicto & 1,92 & 0,75 & 0,46 & 0,82 & & & & \\
\hline 3. Estilo adaptable & 3,02 & 0,82 & 0,42 & 0,32 & 0,74 & & & \\
\hline 4. Estilo dominante & 3,77 & 0,76 & $-0,12$ & $-0,38$ & $-0,07$ & 0,73 & & \\
\hline 5. Estilo evasivo & 2,23 & 0,82 & 0,39 & 0,22 & 0,33 & $-0,06$ & 0,79 & \\
\hline 6. Preferencia por estilo directo & 3,54 & 0,87 & 0,23 & $-0,09$ & 0,23 & 0,38 & $-0,02$ & 0,68 \\
\hline
\end{tabular}

Notas. Las correlaciones mayores a 0,22 resultan significativas al nivel de $p<0,05$, las correlaciones mayores a 0,31 resultan significativas al nivel de $p<0,01$. Los niveles de confiabilidad (Coeficiente Alfa de Cronbach) se hallan expresado sobre la diagonal principal en cursivas.

Tabla 7. Correlaciones y estadísticos descriptivos por factor

\section{Conclusiones}

Este estudio contribuye al desarrollo y validación de una escala para examinar los conflictos comunicacionales en organizaciones interculturales. Los resultados de los análisis practicados revelan que la misma exhibe propiedades psicométricas satisfactorias en términos de su validez de contenido, consistencia interna, estructura factorial, validez convergente y validez discriminante. Si bien algunos ítems fueron eliminados en distintas etapas hasta desarrollar la versión final de la ECCOI, una versión más extensa se encuentra a disposición del lector en la sección Anexo de este artículo, en caso de que alguno de ellos resultara relevante en futuras investigaciones.

Desde el punto de vista de la investigación de la comunicación intercultural, el estudio de los conflictos comunicacionales a los que se enfrentan migrantes y nacionales en instituciones públicas (y privadas) contribuye a identificar diferencias en normas y expectativas culturales de la comunicación que pueden contribuir a la generación de conflictos y/o malestar laboral que afecten no solo al quehacer profesional (ej. Johnstone and Kanitsaki 2009) sino también las relaciones interpersonales entre colegas (véase Lazzaro-Salazar y Pujol-Cols 2017). Como se mencionaba con anterioridad, en Chile esto es particularmente relevan- 
te en contextos interculturales de la salud pública donde las altas exigencias involucradas en la práctica médica requieren de una comunicación efectiva y eficiente y de relaciones laborales positivas (considérese reflexiones en Lindhout et al. 2012). En este sentido, la ECCOI es una herramienta que contribuye al desarrollo de conocimiento sobre los conflictos comunicacionales ayudando a identificar aquellos aspectos de la comunicación intercultural que pueden y/o deben mejorarse. Así, los resultados de esta encuesta pueden contribuir a la formulación y mejora de políticas públicas e institucionales que se sustenten en la visión del desarrollo de la sensibilidad cultural (Anderson et al. 2003; Ulrey and Amason 2001) promoviendo estrategias que fomenten la satisfacción profesional e inclusión social de profesionales migrantes (Weis 2007), al mismo tiempo que contribuyen en garantizar una atención sanitaria de alta calidad y a maximizar la eficiencia del gasto público del sistema de salud (Altshuler et al. 2003).

Además de las contribuciones que esta investigación realiza en el campo de la comunicación intercultural, es necesario reconocer algunas de sus limitaciones para el desarrollo de futuras investigaciones. En primer lugar, el tamaño muestral podría haber sido ligeramente bajo para algunos de los análisis practicados (ej. análisis factorial exploratorio). Sin embargo, y dado que, como se ha explicado en otras secciones del artículo, los médicos migrantes constituyen una población oculta, vulnerable y de difícil acceso, el tamaño muestral obtenido para este estudio resulta adecuado. En este sentido, futuras investigaciones deberían examinar las propiedades psicométricas de la ECCOI en otros contextos organizacionales en los que exista interacción intercultural. En segundo lugar, en este estudio no fue posible analizar la validez predictiva de la ECCOI. Futuras investigaciones podrían examinarla, por ejemplo, vinculando las medidas correspondientes a sus tres sub-escalas (es decir, nivel percibido de conflicto comunicacional, estilo de manejo del conflicto comunicacional y preferencia por un estilo directo de comunicación) con diversas actitudes (ej. satisfacción laboral, compromiso organizacional), comportamientos (ej. acoso laboral), intenciones (ej. intención de cambiar de empleo) e indicadores de bienestar (ej. salud física, salud mental) de interés para la gestión de recursos humanos en contextos interculturales.

\section{Agradecimientos}

Este trabajo fue financiado en todas sus etapas por la Comisión Nacional de Investigación Científica y Tecnológica (CONICYT, Chile), proyecto FONDECYT \# 3160104/2016 titulado Comunicación e Interculturalidad en Instituciones Públicas de la Salud en Chile. 
Mariana Lazzaro-Salazar

Centro de Investigación de Estudios Avanzados

Vicerrectoría de Investigación y Postgrado

Universidad Católica del Maule, Chile.

Avenida San Miguel 3605, Talca

lazzaromari@gmail.com / mlazzaro@ucm.cl

ORCID: 0000-0001-7624-0068
Lucas Pujol-Cols

Facultad de Ciencias Económicas,

Universidad Nacional del Centro de la

Provincia de Buenos Aires, Argentina.

CONICET, Argentina

Pinto 399, Tandil.

lucaspujolcols@gmail.com

ORCID: 0000-0002-8754-3416

Recepción: 20/03/2019; Aceptación: 19/09/2019

\section{Referencias bibliográficas}

Altshuler, L., Sussman, N. y Kachur, E. 2003. Assessing changes in intercultural sensitivity among physician trainees using the intercultural development inventory. International Journal of Intercultural Relations 27 (4): 387-401.

Anderson, L. et al. 2003. Culturally competent healthcare systems: a systematic review. American Journal of Preventive Medicine 24 (3): 68-79.

Ang, S. et al. 2007. "Cultural intelligence: Its measurement and effects on cultural judgment and decision making, cultural adaptation and task performance". Management and Organization Review 3 (3): 335-371.

Blum-Kulka, S. 1987. "Indirectness and politeness in requests: Same or different?” Journal of Pragmatics 11 (2): 131-146.

Boxer, D. 2002. Applying sociolinguistics: Domains and face-to-face interaction (Vol. 15). Amsterdam: John Benjamins.

Brew, F. y Cairns, D. 2004. "Do culture or situational constraints determine choice of direct or indirect styles in intercultural workplace conflicts?" International Journal of Intercultural Relations 28 (5): 331-352.

CASEN 2015. Disponible en: http://www.ministeriodesarrollosocial.gob.cl/pdf/upload/ IDS2.pdf (consultado en abril 2018).

Chan, D. y Goto, S. 2003. "Conflict resolution in the culturally diverse workplace: Some data from Hong Kong employees”. Applied Psychology 52 (3): 441-460.

Clyne, M. 1996. Inter-cultural communication at work: Cultural values in discourse. Cambridge: Cambridge University Press.

Cureton, E. y D’Agostino, R. 1983 Factor Analysis - An Applied Approach. Hillsdale, NJ: Lawrence Erlbaum Associates.

De Dreu, C. et al. 2001. "A theory-based measure of conflict management strategies in the workplace". Journal of Organizational Behavior 22 (6): 645-668.

Editorial, El Mercurio, 2015. Disponible en: http://www.elmercurio.com/blogs/2015/ 03/14/30146/Chile-frente-a-sus-inmigrantes.aspx (consultado en junio 2018).

Editorial, La Tercera, Abril 2015. Disponible en: http://colombiaencl.cl/?p=2623 (consultado en junio 2018)

EFE. Disponible en: http://www.latercera.com/noticia/negocios/2013/04/655-519362-9ministro-larrain-chile-facilitara-inmigracion-para-atraer-trabajadores.shtml (consultado en abril 2018).

Escobar-Pérez, J. y Cuervo-Martínez, A. 2008. "Validez de contenido y juicio de expertos: una aproximación a su utilización”. Avances en Medición 6 (1): 27-36.

Euwema, M. y Van Emmerik, I. 2007. Intercultural competencies and conglomerated conflict behaviors in intercultural conflicts. International Journal of Intercultural Relations 31 (4): 427-441.

Fairclough, N. y Wodak, R. 1997. "Critical discourse analysis". Introduction to Discourse Analysis. van Dijk, T. (Ed.). Newbury Park: Sage. 
Fong, M. 1998. “Chinese immigrants' perceptions of semantic dimensions of direct/indirect communication in intercultural compliment interactions with North Americans”. Howard Journal of Communication 9 (3): 245-262.

Fornell, C. y Larcker, D. 1981. "Evaluating structural equation models with unobservable variables and measurement error". Journal of Marketing Research 18 (1): 39-50.

Goodman, L. 1961, "'Snowball sampling”". The Annals of Mathematical Statistics, 148-170.

Gunnarsson, B. 2013. "Multilingualism in the Workplace". Annual Review of Applied Linguistics 33: 162-189.

Hair, J. et al. 1995. Multivariate data analysis. Englewood Cliffs, NJ: Prentice-Hall.

Hammer, M. 2005. "The intercultural conflict style inventory: A conceptual framework and measure of intercultural conflict resolution approaches". International Journal of Intercultural Relations 29 (6): 675-695.

Harvey, M., Hartnell, C. y Novicevic, M. 2004. "The inpatriation of foreign healthcare workers: A potential remedy for the chronic shortage of professional staff". International Journal of Intercultural Relations 28 (2): 127-150.

Health Statistics of the Organization for Economic Co-operation and Development. Disponible en: http://www.oecd.org/els/health-systems/oecd-health-statistics-2014frequently-requested-data.htm (consultado en abril 2018).

Holland, D., \& Quinn, N. (Eds.). (1987). Cultural models in language and thought. Cambridge University Press.

Holmes, J, Marra, M. y Lazzaro-Salazar, M. 2017. “Negotiating the Tall Poppy Syndrome in New Zealand workplaces: women leaders managing the challenge". Journal of Gender and Language 11 (1): 1-29.

Holmes, J. y Marra, M. 2002. "Having a laugh at work: How humour contributes to workplace culture”. Journal of Pragmatics 34 (12): 1683-1710.

Holmes, J., Marra, M. y Vine, B. 2011. Leadership, Discourse, and Ethnicity. Oxford: Oxford University Press.

Horner, K. y Weber, J. 2008. “The Language Situation in Luxembourg”. Current Issues in Language Planning 9 (1): 69-128.

Huang, C. et al. 2013. "An empirical analysis of the antecedents and performance consequences of using the moodle platform". International Journal of Information and Education Technology 3 (2): 217-221.

Johnstone, M. y Kanitsaki, O. 2009. Engaging patients as safety partners: some considerations for ensuring a culturally and linguistically appropriate approach. Health Policy 90 (1): 1-7.

La Tercera, October 2015. Disponible en: http://www2.latercera.com/noticia/el-papelde-los-medicos-extranjeros-en-consultorios/ (consultado en mayo 2018).

Landaeta, J. y Grün, T. 2011. “Adaptación y Validación de un Cuestionario de Estilos de Manejo de Conflicto Organizacional en una Muestra de Trabajadores de Brasileños”. Revista Psicologia: Organizações e Trabalho 11 (1): 75-89.

Latinoamericano, B. 2017. "Puntos de partida para un pacto global de migración que beneficie a la población en las migraciones y sus gobiernos”. Migración y Desarrollo 15 (29): 137-140.

Lawshe, C. 1975. “A quantitative approach to content validity”. Personnel psychology 28 (4): 563-575.

Lazzaro-Salazar, M. 2009. The Role of/Overlaps \in Intercultural Workplace Interaction. (MA dissertation). Victoria University of Wellington, New Zealand.

Lazzaro-Salazar, M. 2013. Investigating Nurses' Professional Identity Construction in Two Health Settings in New Zealand: Tesis de doctorado, Victoria University of Wellington. Nueva Zelanda.

Lazzaro-Salazar, M. 2016. Downscaling culture in intercultural communication: The case of nurses' professional values in New Zealand. The journey is its own reward: Downscaling culture in Intercultural Communication Research. Cserzö, D., Kantara, A. y Singh, J. (eds.). Cambridge: Cambridge University Press.

Lengua y migración / Language and Migration 12:1 (2020), 123-148

Edición impresa: ISSN 1889-5425. Edición en línea: ISSN 2660-7166. @ Universidad de Alcalá 
Lazzaro-Salazar, M. 2017a. "Ingroups and outgroups in complaints: Exploring politic behaviour in nurses’ discourse”. Logos: Revista de Lingüística, Filosofía y Literatura 27 (2): 319-333.

Lazzaro-Salazar, M. et al. 2015. "Doing power and negotiating through disagreement in public meetings". Journal of Pragmatics and Society 6 (3): 444-464.

Lazzaro-Salazar, M. y Pujol Cols, L. 2017. "Riesgos psicosociales e integración profesional de médicos extranjeros: Un estudio sobre el manejo del conflicto en la zona central de Chile”. Revista Médica de Chile 145 (10): 1300-1307.

Lindhout, P. et al. 2012. "Safety in multilingual work settings: reviewing a neglected subject in European Union policymaking”. European Journal of Language Policy 4 (2): 137-170.

Loewenthal, K. 2001. An introduction to psychological tests and scales. Cornwall, UK: Psychology Press.

Matus, J. 2014. Inmigrantes en Chile: más de dos tercios trabajan y el $42 \%$ cotiza en Fonasa. La Tercera, 20.

Nunnally, J. y Bernstein, I. 1994. Psychological theory. New York: MacGraw-Hill.

Paltridge, B. 2007. Discourse analysis: An introduction. London: Continuum.

Penrod, J. et al. 2003. "A discussion of chain referral as a method of sampling hard-toreach populations". Journal of Transcultural Nursing 14 (2): 100-107.

Pérez, C., Nazar, G., y Cova, F. 2016. "Facilitadores y obstaculizadores de la implementación de la política de salud intercultural en Chile”. Revista Panamericana de Salud Pública 39: 122-127.

Piller, I. 2017. Intercultural communication: A critical introduction. Edinburgh University Press.

Posthuma, R. et al. 2006. "Conflict resolution styles between co-workers in US and Mexican cultures”. International Journal of Conflict Management 17 (3): 242-260.

Rahim, M. 1983. "A measure of styles of handling interpersonal conflict”. Academy of Management Journal 26 (2): 368-376.

Rahim, M. 2001. Managing conflict in organizations (3rd ed.). Westport: Quorum Books.

Ramos, S., Morúa, C. y Ching, A. 2015. “Trabajando con población migrante en Costa Rica: reflexiones sobre la relación entre organizaciones de ayuda y las bases para la acción colectiva”. Revista Rupturas 5 (2): 1-19.

Rizzo, J., House, R. y Lirtzman, S. 1970. "Role conflict and ambiguity in complex organizations”. Administrative Science Quarterly, 150-163.

Roberts, C. y Sarangi, S. 2005. “Theme-oriented discourse analysis of medical encounters". Medical Education 39 (6): 632-640.

Schnurr, S. y Zayts, O. 2017. Language and culture at work. Taylor \& Francis.

Scollon, R. y Scollon, S. 2001. Intercultural Communication: A Discourse Approach. Massachusetts: Blackwell Publishers.

Shachaf, P. 2008. "Cultural diversity and information and communication technology impacts on global virtual teams: An exploratory study”. Information \& Management 45 (2): 131-142.

Sharifian, F. (2017). Cultural linguistics. Ethnolinguistics (Etnolingwistyka), 28, 33-61.

Stefoni, C., Leiva, S. y Bonhomme, M. 2017. "Migración internacional y precariedad laboral. El caso de la industria de la construcción en Chile”. REMHU-Revista Interdisciplinar da Mobilidade Humana 25 (49): 95-112.

Thompson, B. 2004. Exploratory and Confirmatory Factor Analysis. Understanding Concepts and Applications. Washington DC: American Psychological Association.

Thurstone, L. 1935. The reliability and validity of tests. Ann Arbor: Edwards.

Ting-Toomey, S. et al. 1991. "Culture, face maintenance, and styles of handling interpersonal conflict: A study in five cultures". International Journal of Conflict Management 2 (4): 275-296.

Ting-Toomey, S. y Kurogi, A. 1998. "Facework competence in intercultural conflict: An updated face-negotiation theory”. International Journal of Intercultural Relations 22 (2): 187-225.

Tristán-López, A. 2008. "Modificación al modelo de Lawshe para el dictamen cuantitativo de la validez de contenido de un instrumento objetivo”. Avances en Medición 6 (1): 37-48. 
Ulrey, K. y Amason, P. 2001. "Intercultural communication between patients and health care providers: An exploration of intercultural communication effectiveness, cultural sensitivity, stress, and anxiety". Journal of Health Communication 13 (4): 449-463.

Urzúa, A. et al. 2015. "Calidad de vida percibida en inmigrantes sudamericanos en el norte de Chile”. Terapia Psicológica 33 (2): 139-156.

Urzúa, M., Heredia, B. y Caqueo-Urizar, A. 2016. "Mental health and stress by acculturation in immigrants from South America in northern Chile". Revista Médica de Chile 144 (5): 563-570.

Zayts, O. y Lazzaro-Salazar, M. (en prensa). "Healthcare communication in multicultural contexts: Exploring professional mobility”. Applying Linguistics in Illness and Healthcare Contexts. Demjén, Z. (Ed.). London: Bloomsbury.

Zayts, O. y Lazzaro-Salazar, M. 2017a. "Making sense of transitions: Identity construction of migrant doctors in Chile and Hong Kong". Presentada en 7th International Conference on Applied Linguistics and Professional Practice (ALAPP), Ghent, Bélgica, 21-23 Noviembre.

Zayts, O. y Lazzaro-Salazar, M. 2017b. "Does pragmatics matter? Migrant doctors' perceptions of conflict talk: The case of Chile and Hong Kong”. Presentado en 15th International Pragmatics Conference (IPrA), Belfast, Irlanda del Norte, 16-21 Julio.

\section{Anexo: Versión extensa de la ECCOI}

\begin{tabular}{|l|c|c|c|c|}
\hline Sección I: Nivel percibido de conflicto comunicacional & M & DE & $\begin{array}{c}\text { Correlación } \\
\text { ítem-total }\end{array}$ & $\begin{array}{c}\text { Alfa sin } \\
\text { ítem }\end{array}$ \\
\hline Intensidad del conflicto comunicacional & & & & \\
\hline $\begin{array}{l}\text { 1. Los problemas de comunicación a los que me enfrento en mi } \\
\text { trabajo frecuentemente impiden que realice mis labores } \\
\text { satisfactoriamente. }\end{array}$ & 1,78 & 0,95 & 0,74 & 0,74 \\
\hline $\begin{array}{l}\text { 2. Los problemas de comunicación a los que me enfrento en mi } \\
\text { trabajo a menudo me impiden desarrollar relaciones positivas con } \\
\text { mis colegas. }\end{array}$ & 2,24 & 1,19 & 0,75 & 0,74 \\
\hline $\begin{array}{l}\text { 3. Me siento desmotivado/a como resultado de conflictos de } \\
\text { comunicación. }\end{array}$ & 2,23 & 1,26 & 0,85 & 0,70 \\
\hline $\begin{array}{l}\text { 4. Experimento ansiedad a causa de conflictos de comunicación. } \\
\text { 5. Muy frecuentemente los conflictos comunicacionales a los que me } \\
\text { enfrento en mi trabajo terminan en confrontaciones que no conducen } \\
\text { a nada. }\end{array}$ & 2,44 & 1,34 & 0,55 & 0,82 \\
\hline 6. La comunicación con otros colegas es satisfactoria (R) & 1,96 & 0,95 & 0,42 & 0,81 \\
\hline Frecuencia del conflicto comunicacional & 1,22 & 0,85 & 0,70 \\
\hline $\begin{array}{l}\text { 1. Mi forma de comunicación me ha impedido hacer mi trabajo } \\
\text { apropiadamente. }\end{array}$ & 1,55 & 0,86 & 0,75 & 0,79 \\
\hline $\begin{array}{l}\text { 2. La forma en la que se comunican mis colegas chilenos me ha } \\
\text { impedido hacer mi trabajo adecuadamente. }\end{array}$ & 1,80 & 1,05 & 0,85 & 0,75 \\
\hline $\begin{array}{l}\text { 3. En mi lugar de trabajo me enfrento a conflictos de comunicación } \\
\text { con mis colegas chilenos. }\end{array}$ & 2,23 & 0,99 & 0,84 & 0,75 \\
\hline \begin{tabular}{l} 
4. Tengo problemas de comunicación con mis colegas chilenos. \\
\hline 5. Se burlan de mi forma de hablar.
\end{tabular} & 1,88 & 0,92 & 0,77 & 0,78 \\
\hline
\end{tabular}




\begin{tabular}{|c|c|c|c|c|}
\hline Sección II: Estilo de manejo del conflicto comunicacional & M & $\mathrm{DE}$ & $\begin{array}{l}\text { Correlación } \\
\text { ítem-total }\end{array}$ & $\begin{array}{c}\text { Alfa sin } \\
\text { ítem }\end{array}$ \\
\hline \multicolumn{5}{|l|}{ Estilo de manejo del conflicto: Adaptable } \\
\hline 1. Otros colegas suelen corregirme si digo algo inapropiadamente. & 2,35 & 0,89 & 0,23 & 0,68 \\
\hline $\begin{array}{l}\text { 2. Siento que los colegas chilenos adaptan su forma de comunicarse } \\
\text { cuando están conmigo. }\end{array}$ & 2,29 & 1,18 & 0,29 & 0,69 \\
\hline 3. Debo adaptar mi forma de comunicarme con los colegas chilenos. & 3,33 & 1,23 & 0,69 & 0,60 \\
\hline $\begin{array}{l}\text { 4. Tuve que adaptar la forma de comunicarme cuando comencé a } \\
\text { trabajar en Chile. }\end{array}$ & 3,61 & 1,30 & 0,61 & 0,62 \\
\hline $\begin{array}{l}\text { 5. Debería mejorar la forma de comunicarme con mis colegas } \\
\text { chilenos. }\end{array}$ & 2,60 & 1,16 & 0,63 & 0,61 \\
\hline $\begin{array}{l}\text { 6. Debería cambiar la forma de comunicarme con mis colegas } \\
\text { chilenos. }\end{array}$ & 2,30 & 1,08 & 0,55 & 0,63 \\
\hline $\begin{array}{l}\text { 7. La comunicación con mis colegas chilenos ha mejorado con el paso } \\
\text { del tiempo. }\end{array}$ & 3,89 & 1,09 & 0,41 & 0,66 \\
\hline $\begin{array}{l}\text { 8. Prefiero buscar diferentes maneras de dar a entender lo que } \\
\text { quiero comunicar. }\end{array}$ & 3,58 & 1,03 & 0,61 & 0,62 \\
\hline $\begin{array}{l}\text { 9. Participo activamente dando mi opinión y compartiendo mis } \\
\text { experiencias en diversos contextos laborales. }\end{array}$ & 4,03 & 0,99 & 0,26 & 0,69 \\
\hline $\begin{array}{l}\text { 10. Prefiero adecuarme a la forma de comunicarse de la otra } \\
\text { persona. }\end{array}$ & 3,26 & 1,08 & 0,66 & 0,61 \\
\hline \multicolumn{5}{|l|}{ Estilo de manejo del conflicto: Dominante } \\
\hline $\begin{array}{l}\text { 1. Me las arreglo solo/a para resolver los problemas de comunicación } \\
\text { con éxito. }\end{array}$ & 3,93 & 1,09 & 0,50 & 0,73 \\
\hline 2. Mis habilidades de comunicación son las más efectivas. & 4,03 & 0,97 & 0,75 & 0,57 \\
\hline $\begin{array}{l}\text { 3. Mi forma de comunicación ha sido una ventaja cuando se trata de } \\
\text { situaciones conflictivas. }\end{array}$ & 3,64 & 1,08 & 0,66 & 0,64 \\
\hline $\begin{array}{l}\text { 4. Sé exactamente lo que se espera de mí en lo que respecta a la } \\
\text { forma de comunicación. }\end{array}$ & 3,61 & 1,07 & 0,68 & 0,62 \\
\hline 5. Siento que mi forma de comunicación me beneficia. & 3,81 & 0,97 & 0,75 & 0,56 \\
\hline 6. Intento que los demás adecuen su forma de comunicación a la mía. & 2,23 & 0,99 & 0,30 & 0,68 \\
\hline \multicolumn{5}{|l|}{ Estilo de manejo del conflicto: Evasivo } \\
\hline 1. A menudo evito decir que no comprendo. & 2,09 & 1,12 & 0,30 & 0,70 \\
\hline $\begin{array}{l}\text { 2. Evito aclarar algo cuando no se comprendió lo que intenté } \\
\text { comunicar. }\end{array}$ & 2,06 & 1,22 & 0,25 & 0,72 \\
\hline 3. Evito involucrarme en conversaciones conflictivas. & 3,76 & 1,20 & 0,46 & 0,68 \\
\hline $\begin{array}{l}\text { 4. Cuando me veo envuelto en conflictos de comunicación espero a } \\
\text { que mis colegas chilenos me ayuden a resolverlo. }\end{array}$ & 2,60 & 1,11 & 0,35 & 0,69 \\
\hline 5. A veces los conflictos comunicacionales quedan sin ser resueltos. & 2,43 & 1,20 & 0,41 & 0,68 \\
\hline 6. Prefiero no expresar estar en desacuerdo con alguien. & 2,39 & 1,19 & 0,75 & 0,60 \\
\hline 7. Intento no hablar en reuniones de equipo. & 1,89 & 1,01 & 0,74 & 0,61 \\
\hline $\begin{array}{l}\text { 8. Prefiero encontrar otro momento para aclarar malentendidos } \\
\text { comunicacionales. }\end{array}$ & 2,65 & 1,24 & 0,65 & 0,63 \\
\hline 9. Prefiero dejar pasar los conflictos de comunicación. & 1,99 & 0,88 & 0,61 & 0,64 \\
\hline 10. Prefiero no expresar mis opiniones de manera abierta. & 2,23 & 1,21 & 0,64 & 0,63 \\
\hline
\end{tabular}


Comunicación intercultural en instituciones públicas de la salud..

\begin{tabular}{|l|c|c|c|c|}
\hline $\begin{array}{l}\text { Sección III: Grado de preferencia por un estilo de lenguaje } \\
\text { directo }\end{array}$ & $M$ & $\mathrm{DE}$ & $\begin{array}{c}\text { Correlación } \\
\text { ítem-total }\end{array}$ & $\begin{array}{c}\text { Alfa sin } \\
\text { ítem }\end{array}$ \\
\hline 1. Me incomoda el uso de lenguaje directo (R) & 3,90 & 0,96 & 0,41 & 0,68 \\
\hline $\begin{array}{l}\text { 2. Me siento más cómodo/a comunicando mis opiniones de manera } \\
\text { directa. }\end{array}$ & 4,09 & 0,93 & 0,73 & 0,37 \\
\hline 3. Me incomoda el uso de lenguaje indirecto. & 3,50 & 1,25 & 0,75 & 0,41 \\
\hline 4. Me resulta difícil comprender el lenguaje indirecto. & 3,04 & 1,18 & 0,72 & 0,42 \\
\hline
\end{tabular}

Lengua y migración / Language and Migration 12:1 (2020), 123-148

Edición impresa: ISSN 1889-5425. Edición en línea: ISSN 2660-7166. (C) Universidad de Alcalá 